\title{
Identification of Key Patches for Biodiversity Conservation Based on Possibility of Connectivity Method
}

\author{
Yue Zhang1, a, Bo Song1, b, Zaiqiang Liu'², c, Fan Zhang ${ }^{1, d}$ \\ ${ }^{1}$ Department of Environmental Engineering, School of Energy and Environmental Engineering, \\ University of Science and Technology Beijing, Xueyuan Road 30, Beijing 100083, China \\ ${ }^{2}$ Tianjin BinHaiKeWei Patent Trademark Agency Ltd. No.8 Huatiandao Street, Binhai hi-tec industry \\ development zone, Tianjin 300450, P.R. China \\ azhangyue06329@163.com, bsongbo@pku.eud.cn, cliuzai.qiang@163.com, \\ dzhangfan815@126.com
}

Keywords: reclassification of biodiversity value, PC index, ecosystem services value, landuse type, key patches.

Abstract: Currently, large amount of habitats of wildlife have been displaced by artificial structures because of urban expansion. As a result, smaller patches of habitat have been lost, larger patches have become fragmented, and some of the habitats become lonely islands which will have weaker and weaker contact with outside. Therefore, the optimization of landscape structure will benefit more for biodiversity conservation by analyzing the best landscape layout as the patches have been rapidly lost. In this article, we have analyzed and reclassified the spatial pattern of the value of biodiversity based on the possibility of connectivity method which enabled the possibility of the identification of key patches. In the results, we have found that biodiversity value was not evenly distributed with patch area because of the difference of connectivity. Key patches of Beijing have been classified into three categories: (1) patches with larger area; (2) satellite patches around large patches; (3) stepping-stone patches with high connectivity.

\section{Introduction}

Ecosystem service is benefit that human obtained from natural system [1], which is the cornerstone of the survival of mankind and the modern civilization [2]. The loss of ecosystem service will severely affect the sustainable development. Biodiversity as an important kind of ecosystem service is the regulator of ecological process which is able to be evaluated on some level [3]. However, biodiversity and habitats have been degraded and fragmentized due to human activities and disturbance, which is the main cause of biodiversity recession. For example, global biodiversity has declined about $12 \%[4,5]$. By 2020, at the current rate of biodiversity loss, the world could have witnessed a two-thirds decline in global wildlife populations in only half a century [6].

The protection of biodiversity should be proceeded with the maintaining of biodiversity conservation [7] and identified the area of high value density. The assessment of biodiversity value mainly followed the traditional method which was represented by Costanza [8]. Traditional method usually consider patch area as the only factor that related to biodiversity value. Actually, spatial pattern is also a crucial factor affects the biodiversity value which has not been fully considered in current researches $[9,10]$. Currently, rarely studies applied landscape pattern to the assessment of biodiversity value [11]. Pelorossoa et al. used landscape connectivity to evaluate ecosystem services value of Bari, Italy [12]. Cho $\mathrm{Nam} \mathrm{Ng}$ et al. applied possibility of connectivity index to evaluate the biodiversity value of Shenzhen river of 1988 and 2008. Kreuter et al. thought that patch area, edge effect, proximity, and corridors could be integrated in related index to evaluate ecosystem services [14].

Our aim is to take Beijing as case area to identify key patches based on possibility of connectivity method. We have divided Beijing into five land use types which are forest, grassland, cultivated land, 
construction land, and water area. Among those, forest and grass land have been analyzed to illustrate the identification process in the article. We are expected to identify those patches with high value density and important connectivity.

\section{Material and method}

\section{Study area}

Beijing is located in $115.7^{\circ}-117.4^{\circ}$ east longitude and $39.4^{\circ}-41.6^{\circ}$ north latitude. It covers 16,807 square kilometers, of which $62 \%$ is mountainous and $40 \%$ is forest. There are multiple types of ecosystems in Beijing where biodiversity is very rich. It has 16 districts which are Dongcheng, Xicheng, Haidian, Chaoyang, Fengtai, Mentougou, Shijingshan, Fangshan, Tongzhou, Shunyi, Changping, Daxing, Huairou, Pinggu, Yanqing, and Miyun. During last decades, the habitat of Beijing has been reduced severely, and some of the patches even become separated landscape which has weaken the material flow, energy flow, and information flow. Genetic exchange has been blocked among patches which is against the biodiversity conservation in overall landscape.

\section{Method}

The identification of the key patches of great biodiversity conservation will be divided into two procedures: reclassification and identification. In the reclassification phase, a patch will be reclassified from three values into two values. Usually, there are three kinds of values belong to one patch [15]: (1) internal value; (2) value that acts as a starting or ending patch in the migration path; (3) stepping stone value. As we can see from Eq.1 and Eq.2.

$$
\begin{aligned}
& \mathrm{dPC}_{\mathrm{ki}}=\mathrm{dPCintra}_{\mathrm{ki}}+\mathrm{dPCflux}_{\mathrm{ki}}+\mathrm{dPC} \text { ennector }_{\mathrm{ki}} \\
& \operatorname{ESVB}(\mathrm{PC})_{\mathrm{ki}}=\mathrm{ESVB}(\mathrm{PC}) \text { intra }_{\mathrm{ki}}+\mathrm{ESVB}(\mathrm{PC}) \text { flux }_{\mathrm{ki}}+\mathrm{ESVB}(\mathrm{PC}) \text { connector }_{\mathrm{ki}}
\end{aligned}
$$

Where $\mathrm{dPC}_{\mathrm{ki}}$ indicates the connectivity importance of patch $\mathrm{i}$ in land use $\mathrm{k}$. dPCintra $\mathrm{ki}$ is the contribution of the internal area of patch $i$ to the overall connectivity of $k$. dPCflux $x_{k i}$ is the contribution of patch $i$ as a starting or ending point to the overall connectivity. dPCconnector ki $_{\text {is }}$ the contribution of patch $\mathrm{i}$ as stepping stone with maximum product probability to the overall connectivity. $\operatorname{ESVB}(\mathrm{PC})_{\mathrm{ki}}$ is biodiversity value of patch $\mathrm{i}$ of $\mathrm{k}$. $\mathrm{ESVB}(\mathrm{PC})$ intra $_{\mathrm{ki}}$ is biodiversity value that provided by the internal area of patch $i$. $\operatorname{ESVB}(\mathrm{PC})$ flux $_{\mathrm{ki}}$ is biodiversity value of patch $\mathrm{i}$ as a starting or ending point in the path. $\operatorname{ESVB}(\mathrm{PC})$ connector $_{\mathrm{ki}}$ is biodiversity value of patch $\mathrm{i}$ as stepping stone patch.

For the calculation of $\mathrm{dPC}_{\mathrm{ki}}$ and $\operatorname{ESVB}(\mathrm{PC})_{\mathrm{ki}}$ and three of their values respectively, we will consider both habitat size and spatial connectivity [13,15], as we can see from Eq.3 and Eq.4.

$$
\begin{aligned}
& \operatorname{ESVB}(\mathrm{PC})_{\mathrm{k}}=\sum_{\mathrm{i}}\left[\mathrm{VC}_{\mathrm{k}} \times\left(\mathrm{A}_{\mathrm{kmax}} / \mathrm{dPC}_{\mathrm{kmax}}\right) \times \mathrm{dPC}_{\mathrm{ki}}\right] \\
& \mathrm{dPC}_{\mathrm{ki}}=\left(\mathrm{PC}_{\mathrm{ki}}-\mathrm{PC}^{\prime}{ }_{\mathrm{ki}}\right) / \mathrm{PC}_{\mathrm{ki}} \times 100
\end{aligned}
$$

Where $\operatorname{ESVB}(\mathrm{PC})_{\mathrm{k}}$ is the biodiversity value of land use $\mathrm{k}$, and $\mathrm{VC}_{\mathrm{k}}$ is the coefficient of $\mathrm{k}$. $\mathrm{A}_{\mathrm{k}-\max }$ is to the largest patch among $\mathrm{k}$. $\mathrm{dPC}_{\mathrm{k}-m a x}$ indicates the maximum value of $\mathrm{dPC}$ among $\mathrm{k}$.

Based on equation (1) to (4), we have reclassified $\operatorname{ESVB}(\mathrm{PC})_{\mathrm{ki}}$ into two values which are internal value and external value. As we can see from Eq.5 to Eq.7.

$$
\begin{aligned}
& \operatorname{ESVB}(\mathrm{PC})_{\mathrm{ki}}=\operatorname{ESVB}(\mathrm{PC}) 1_{\mathrm{ki}}+\operatorname{ESVB}(\mathrm{PC}) 2_{\mathrm{ki}} \\
& \operatorname{ESVB}(\mathrm{PC}) 1_{\mathrm{ki}}=\operatorname{ESVB}(\mathrm{PC}) \mathrm{intra}_{\mathrm{ki}}+\operatorname{ESVB}(\mathrm{PC}) \text { flux }_{\mathrm{ki}} / 2 \\
& \operatorname{ESVB}(\mathrm{PC}) 2_{\mathrm{ki}}=\operatorname{ESVB}(\mathrm{PC}) \text { flux }_{\mathrm{ki}} / 2+\operatorname{ESVB}(\mathrm{PC}) \text { connector }_{\mathrm{ki}}
\end{aligned}
$$


Where $\operatorname{ESVB}(\mathrm{PC}) 1_{\mathrm{ki}}$ is the biodiversity value that patch $\mathrm{i}$ contributes to itself, or internal value, $\mathrm{ESVB}(\mathrm{PC}) 2_{\mathrm{ki}}$ is the ES value that provided by patch i to other patches, or external value.

In the phase of identification, we think that key patches will be of high $\operatorname{ESVB}(\mathrm{PC}) 1_{\mathrm{ki}}$ or high $\operatorname{ESVB}(\mathrm{PC}) 2_{\mathrm{ki}}$. In this article, we have defined high $\operatorname{ESVB}(\mathrm{PC}) 1_{\mathrm{ki}}$ will be the patches with value 3 times higher than the average unit value of $\operatorname{ESVB}(\mathrm{PC}) 1_{\mathrm{ki}}$. In the meantime, high $\operatorname{ESVB}(\mathrm{PC}) 2_{\mathrm{ki}}$ will be the patches with value 3 times higher than the average unit value of $\operatorname{ESVB}(\mathrm{PC}) 2 \mathrm{ki}$. As we can see from Eq.8 and Eq.9.

$$
\begin{aligned}
& \left(\operatorname{ESVB}(\mathrm{PC}) 1_{\mathrm{ki}} / \mathrm{A}_{\mathrm{ki}}\right) \geq 3 \times\left(\sum{ }_{1}{ }^{\mathrm{E}} \operatorname{ESVB}(\mathrm{PC}) 1_{\mathrm{ki}} / \mathrm{A}_{\mathrm{ki}} / \mathrm{n}\right) \\
& \left(\operatorname{ESVB}(\mathrm{PC}) 2_{\mathrm{ki}} / \mathrm{A}_{\mathrm{ki}}\right) \geq 3 \times\left(\sum{ }_{1}{ }^{\mathrm{n}} \operatorname{ESVB}(\mathrm{PC}) 2_{\mathrm{ki}} / \mathrm{A}_{\mathrm{ki}} / \mathrm{n}\right)
\end{aligned}
$$

\section{Result and discussion}

We have calculated grassland and forest as examples to illustrate the results of both key patches of high internal value $\left(\mathrm{ESVB}(\mathrm{PC}) 1_{\mathrm{ki}}\right)$ and high external value $\left(\mathrm{ESVB}(\mathrm{PC}) 2_{\mathrm{ki}}\right)$ based on the statistics of 2010 of Beijing. It was shown as Fig. 1 and Fig. 2.

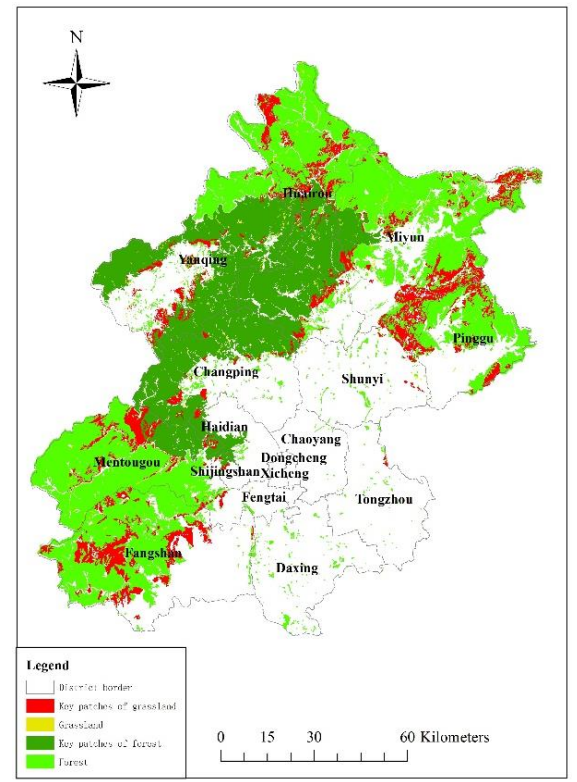

Fig.1 Key patches of high internal value

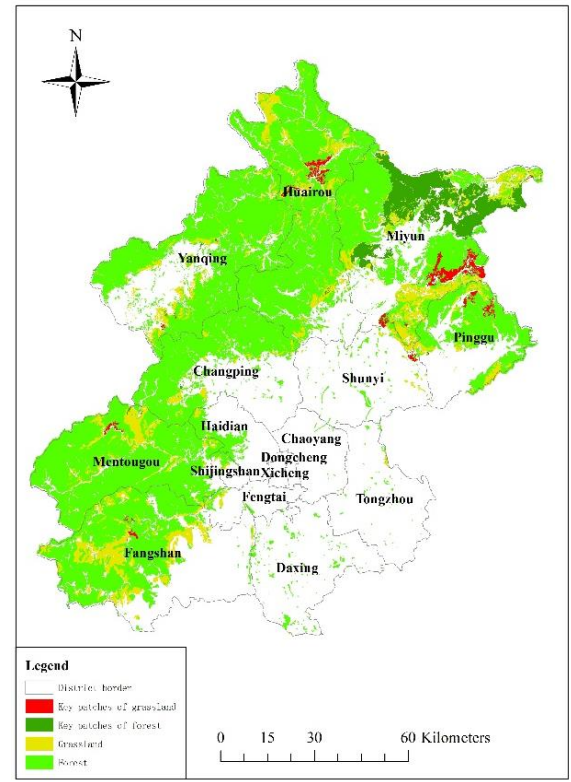

Fig.2 Key patches of high external value

As it has been illustrated in Fig. 1, ESVB(PC)1 has a relatively higher relation with patch area, which means that larger patches usually have higher $\operatorname{ESVB}(\mathrm{PC}) 1$ or invernal value and vice versa. Forests with higher invernal value locate in the west part of Beijing are consist of 36 patches, which includes 1 larger patch and 35 smaller patches. While among the 36 patches, the largest of which has the highest $\operatorname{ESVB}(\mathrm{PC})$ flux $_{\mathrm{ki}}$ value as starting or ending point. What's more, that patch has radiation and driving function of the surrounding 35 smaller patches. As it is evaluated by Eq. 7, the 35 smaller patches have higher ESVB(PC) flux $\mathrm{ki}_{\mathrm{i}}$ value because of the largest patch. Same as forest, grassland or even cultivated land and water area are consist of a largest patch and some smaller patches. From Fig.1 we can conclude that patch area has positive effect for ESVB(PC)1. Therefore, large patch usually has higher $\operatorname{ESVB}(\mathrm{PC}) 1$ value, and under the influence of the large patch, the smaller surrounding patches also will have higher $\operatorname{ESVB}(\mathrm{PC}) 1$ value.

As we can see from Fig. 2, ESVB(PC)2 has weaker relations with patch area which is mainly determined by the landscape connectivity. Higher ESVB(PC)2 patches of forest locate in Miyun district, the northeast of Beijing. The highest patch is the bridge of the east and west forests. Higher grassland is also located in the stepping-stone position which means the loss of these patches will bring down the diffusion rate or lose the corridors of the patches. 


\section{Conclusions}

Key patches of Beijing have been identified based on PC method of 2010. In this article, we integrated three kinds of biodiversity values into two categories: $\operatorname{ESVB}(\mathrm{PC}) 1_{\mathrm{ki}}$ and $\mathrm{ESVB}(\mathrm{PC}) 2_{\mathrm{ki}}$. The reclassification was beneficial to the ES trade-off and the formulation of payments for ecosystem services scheme. Large patches were important for maintaining connectivity, but the small patches in the connecting position also played an important role in the overall connectivity. Patches located in the connecting position should be protected in order to reduce the loss of ESVB(PC). In this article, we identified patches with high density of value. Special protection areas could be designated according to the result of the research. This method could achieve a multiplier effect in biodiversity conservation.

\section{Acknowledgements}

This paper is based on a workshop funded by the National Natural Science Foundation of China (No. 71173013). We thank all experts that have been consulted as part of the research conducted.

\section{References}

[1] Millennium Ecosystem Assessment. Ecosystems and Human Well-being: Biodiversity Synthesis[M]. World Resources Institute. Washington, DC. (2005)

[2] J. F. Feng, Y. Li, L. Zhu. Discrimination of concepts of ecosystem functions and ecosystem services. Ecology and Environmental Sciences, 18(4), 1599-1603, in Chinese. (2009)

[3] M.G. Mace, K. Norris, H.A. Fitter. Biodiversity and ecosystem services: a multilayered relationship, Trends in Ecology and Evolution, 27, 1, 19-26. (2012)

[4] WWF-INT Annual Review 2011.

http://d2ouvy59p0dg6k.cloudfront.net/downloads/annual_report_2011.pdf. (2011)

[5] United Nations Environment Programme Annual Report 2015.

http://web.unep.org/annualreport/2015/en/index.html. (2015)

[6] WWF-INT Annual Review 2015. http://wwf.panda.org/about_our_earth/all_publications/.(2015)

[7] E. Lazarus, D. Lin, J. Martindill, J. Hardiman, L. Pitney, A. Galli. Biodiversity Loss and the Ecological Footprint of Trade. Diversity, 7, 170-191. (2015)

[8] R. Costanza, R. d'Arge, R. d'Groot, S. Farber, M. Grasso, B. Hannon, K. Llmburg, S. Naeem, R.V. O’Nell, J. Paruelo, R.G. Raskln, P. Sutton, M. van den Belt. The value of the world's ecosystem services and natural capital. Nature, 387, 253-260. (1997)

[9] S. Frank, C. Fürst, L. Koschke, F. Makeschin, A contribution towards a transfer of the ecosystem service concept to landscape planning using landscape metrics. Ecological Indicators, 21, 30-38. (2012)

[10] R.U. Syrbe, U. Walz. Spatial indicators for the assessment of ecosystem services: providing, benefiting and connecting areas and landscape metrics. Ecological Indicators, 21, 80-88. (2012)

[11] G.D. Xie, Y. Xiao, C.X. Lu. Study on ecosystem services: Progress, limitation, and basic paradigm. Journal of Plant Ecology, 30, 2, 191-199, in Chinese. (2006)

[12] R. Pelorossoa, F. Gobattonia, F. Gerib, R. Monacoc, A. Leone. Evaluation of ecosystem services related to bio-energy landscape connectivity (belc) for land use decision making across different planning scales. Ecological Indicators, 61, 114-129. (2015)

[13] C.N. Ng, Y.J. Xie, X.J. Yu. Integrating landscape connectivity into the evaluation of ecosystem services for biodiversity conservation and its implications for landscape planning. Applied Geography, 42, 1-12. (2013)

[14] U.P. Kreuter, H.G. Harris, M.D. Matlock, R.E. Lacey. Change in ecosystem service values in the San Antonio area, Texas. Ecological Economics, 39, 3, 333-346. (2001)

[15] S. Saura, L. Rubio. A common currency for the different ways in which patches and links can contribute to habitat availability and connectivity in the landscape. Ecography, 33, 3, 523-537. (2010) 